\title{
India struggles to cope with IT brain drain
}

\section{K. S. Jayaraman, New Delhi}

Scientific research in India is facing up to a brain drain with a difference. The financial lure of careers in information technology - at home and abroad — is creaming off more and more of the talented young people who might otherwise become scientists.

Addressing the Indian Science Congress last month, Prime Minister Atal Behari Vajpayee said the global demand for Indian computer professionals was a challenge for Indian science. Although the country was proud of its prowess in IT, Vajpayee said, he was worried about the decline in enrolment in other disciplines by the country's best students. $\mathrm{He}$ warned that the trend could lead to a shortage of science teachers and researchers.

The state of Tamilnadu, one of the main sources of IT émigrés, reports a shortage of 500 university teachers, with few graduates choosing to go on to do a $\mathrm{PhD}$, the entry-level qualification for institute faculty.

"All our best students are opting for IT," says one university administrator. "This is posing problems for our other faculties."

The head of the Defence Research and Development Organisation recently blamed a delay in developing a new fighter aircraft on a severe shortage of skilled staff. And many research institutes are feeling the impact.

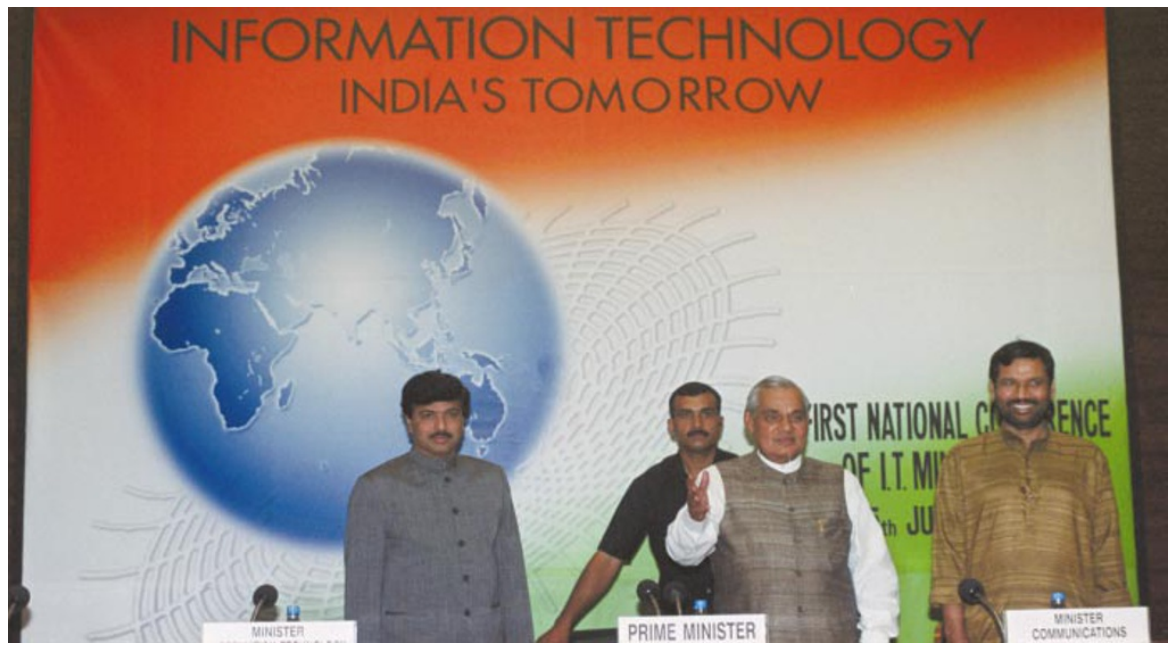

Feed the world: Vajpayee (second from right) plans to step up supply of scientists and IT professionals.

"I would like to believe this is a passing phase and that things will stabilize sooner rather than later," says Govardhan Mehta, president of the Indian National Science Academy and director of the Indian Institute of Science in Bangalore, the country's leading research institute. Many science and engineering students at his institute have left for high-paying jobs in the IT sector, he adds.

Even India's own IT industry has been hit. "The attraction of the United States has led to a severe shortage of high-quality talent," says Naresh Gupta, managing director of Adobe India.

The government's main response has been to increase the supply of IT professionals, including teachers, announcing plans to expand undergraduate training and emphasize postgraduate and research programmes. It also plans to sponsor 200 students in all scientific disciplines to $\mathrm{PhD}$ level and upgrade 250 university science departments.

One estimate is that India will need to produce 1.5 million computer software engineers - half of whom will go abroad during the next eight years.

Indian nationals are said to be involved in $40 \%$ of the start-up companies in California's Silicon Valley. The flow increased after the annual quota of US work permits for technically qualified immigrants went up from 107,500 to 195,000. Britain has tripled its quota to 90,000. Singapore, Japan and Germany are also taking steps to attract skilled immigrants.

\section{NASA celebrates as spacecraft homes in on asteroid}

\section{William Triplett, Washington}

Next Monday, 12 February, NASA scientists will be celebrating the success of the Near Earth Asteroid Rendezvous (NEAR) mission - even if the spacecraft crashes and disintegrates on the surface of the asteroid on which it will attempt to land.

This is because NEAR has already surpassed its original goals. The attempted landing, according to NASA spokesman Don Savage, is merely a chance to collect "bonus science" in the form of extremely highresolution photographs that the spacecraft will take as it descends towards 433 Eros.

"Even if we just get one photograph," Savage says, "it will be more than we expected.” There is an outside possibility that NEAR's instruments will survive a landing, because 433 Eros has only a weak gravitational pull. But NEAR was not designed for landing, and no one has tried landing a spacecraft on an asteroid before.

NEAR Shoemaker, as the mission is formally known, was launched five years ago. After a two-billion-mile journey, it entered the orbit of 433 Eros, one of the largest near-Earth asteroids. The spacecraft then began collecting data for the first longterm, close-up study of an asteroid. It focused on mass, structure, composition, geology and magnetic field, in a search for clues to the origins of the Earth, the other planets, and possibly the entire Universe.

According to NASA, NEAR has collected 10 times more data than originally planned during its one-year orbit of 433 Eros, including indications that the asteroid is older than Earth. But some of the data have been mystifying, such as the disintegration of boulders on the asteroid's surface. Such questions prompted scientists at NASA and Johns Hopkins University's Applied Physics Laboratory, which built the craft and has managed the mission, to try for a closer look.

The success of the $\$ 240$ million mission marks a welcome contrast with the failures and cutbacks in NASA's outer-planet programme during recent years.

Mark Sykes, chair of the American Astronomical Society's division of planetary sciences, supports the NASA plan: "Why just turn the thing off at the end when you can do something that's higher risk and you can gain from it?"

http://near.jhuapl.edu

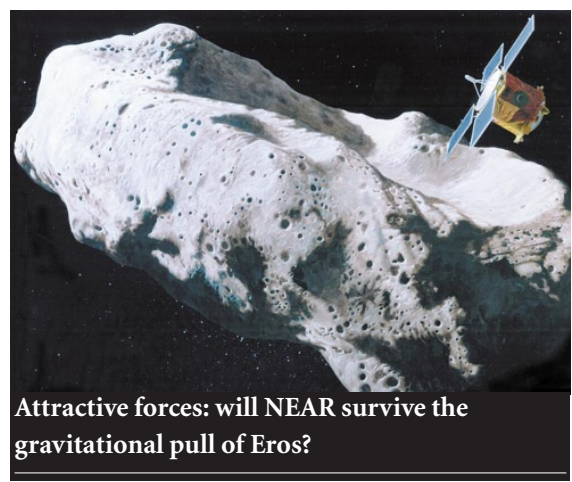

